\title{
Prognosis of Patients with Pregnancy Hypertensive Disorders Followed in University Hospital to Parzakou in 2020
}

\author{
Serge Hugues Mahougnon Dohou ${ }^{{ }^{*}}$, Houétondji Léopold Codjo', Mahublo Vinadou Vodouhè ${ }^{1}$, \\ Urielle Didavi', Djidjoho Arnaud Sonou33, Mahouna Philippe Adjagba ${ }^{3}$, \\ Murielle Kayivi Hounkponou ${ }^{3}$, Olaniran Alphonse Biaou ${ }^{4}$, Nicolas Amègan5, \\ Dèdonougbo Martin Houénassi ${ }^{3}$
}

${ }^{1}$ Cardiology Teaching and Research Unit, Departmental University Hospital of Borgou, University of Parakou, Parakou, Benin ${ }^{2}$ University Clinic for Gynaecology and Obstetrics, Departmental University Hospital of Borgou, University of Parakou, Parakou, Benin

${ }^{3}$ University Cardiology Clinic, HKM National Hospital and University Center in Cotonou, University of Abomey-Calavi, Cotonou, Benin

${ }^{4}$ Regional Institute of Public Health, University of Abomey-Calavi, Cotonou, Benin

${ }^{5}$ Doctoral School of Health Sciences, University of Abomey-Calavi, Cotonou, Benin

Email: ^huguesdohou@gmail.com

How to cite this paper: Dohou, S.H.M., Codjo, H.L., Vodouhè, M.V., Didavi, U., Sonou, D.A., Adjagba, M.P., Hounkponou, M.K., Biaou, O.A., Amègan, N. and Houénassi, D.M. (2021) Prognosis of Patients with Pregnancy Hypertensive Disorders Followed in University Hospital to Parzakou in 2020. World Journal of Cardiovascular Diseases, 11, 378-388.

https://doi.org/10.4236/wjcd.2021.118037

Received: June 2, 2021

Accepted: August 24, 2021

Published: August 27, 2021

\section{Copyright (C) 2021 by author(s) and} Scientific Research Publishing Inc. This work is licensed under the Creative Commons Attribution International License (CC BY 4.0).

http://creativecommons.org/licenses/by/4.0/

\begin{abstract}
Introduction: Hypertensive disorders of pregnancy (HDP) are often accompanied by cardiovascular sequelae. The objective of this study was to describe the prognosis in the postpartum period of patients with HDP in Departmental University Hospital of Borgou CHUD-B from Parakou in 2020. Methods. The study was prospective with a descriptive and analytical design and was conducted from January 2020 to September 2020. Patients with HDP were recruited from the gynecology-obstetrics department and each followed for 3 months in the cardiology department. HDP was classified according to the International Society for the Study of Hypertension in Pregnancy, and blood pressure (BP) was taken according to WHO recommendations. Self-measurement of $\mathrm{BP}$ at home was performed to assess blood pressure control outside the hospital. Epidata 3.1 and SPSS 21 software were used for data processing and analysis. $\mathrm{P}$ values $<5 \%$ were considered statistically significant. Results. During the study period, the hospital frequency of HDP was $15.6 \%$. The frequency of maternal complications in the postpartum period was $28 \%$ (severe hypertension: $23.2 \%$; eclampsia: $3.6 \%$; puerperal psychosis: $1.2 \%$ ). At the end of the three-month follow-up, blood pressure returned to normal in $73.2 \%$ of cases; it persisted in $26.8 \%$ of women. Factors associated with persistence of hypertension after multivariate analysis were, overweight/obesity RRa 8.664 [1.566 - 47.941], $(\mathrm{p}=0.013)$; family history of hypertension RRa 6.499 [1.493
\end{abstract}


- 28.289], $(\mathrm{p}=0.013)$; history of hypertension in previous pregnancies $\mathrm{RRa}$ 7.764 [1.561 - 38.601], $(\mathrm{p}<0.012)$. Conclusion: The frequency of HDP is not negligible at CHUD-B/A. The evolution of these HDP was marked in more than a quarter of cases by complications in the postpartum period followed by a persistence of hypertension 3 months after childbirth predicted by cardiovascular risk factors.

\section{Keywords}

Hypertensive Disorders of Pregnancy, Post Partum, Prognosis, Parakou

\section{Introduction}

Hypertensive disorders of pregnancy (HDP) affect about 10\% - 15\% of pregnant women [1] [2]. They are a specific cardiovascular risk factor. For many women, they represent a gateway to chronic cardiovascular disease, as several studies have shown. Indeed, in 1986 in the United States, a comparative study by Sibai et al. found an incidence of $14.8 \%$ of hypertension in women with pre-eclampsia compared to $5.6 \%$ in those with a normal pregnancy [3]. In Italy, Festa et al. in 2017 found a $10.6 \%$ prevalence of post-pregnancy hypertension in women who had hypertension during pregnancy [4]. Timpka et al. in the USA reported in a study published in 2017 that $10 \%$ of women diagnosed with chronic hypertension had a history of hypertensive disorder in pregnancy [5]. In Yaoundé in 2018, Amougou et al. found an incidence of $2.8 \%$ of hypertension in women with a history of pre-eclampsia [6]. This shows that HDP can lead to chronic hypertension exposing the patient to its multiple complications [7]. In Benin, a study carried out in 1996 at the National Hospital and University Center in Cotonou reported a prevalence of $7.6 \%$ of hypertension during pregnancy, including $26.4 \%$ of pre-eclampsia [8]. In Parakou, in 2015 at the University and departmental hospital of Borgou in the north of Benin, the frequency of hypertension in pregnancy was $6.2 \%$ including $33.9 \%$ of pre-eclampsia [9]. The frequency of severe pre-eclampsia was $4.7 \%$ in 2012 [10] and 5.6\% in 2015 [11] at University and Departmental Hospital of Borgou. Despite these significant figures, the outcome of women with HDP remains poorly documented in our country. Knowing that hypertension during pregnancy strongly increases the risk of developing chronic arterial hypertension, we initiate this work to evaluate the prognosis, in the postpartum period, of patients suffering from HDP in order to appreciate the extent of the phenomenon in our country and to contribute to a better prevention.

\section{Methods}

This is a prospective longitudinal study with descriptive and analytical aims which took place over a period of (09) months, from 06 January to 06 September 2020 in the gyneco-obstetric and cardiology departments of the University and Departmental Hospital of Borgou. The study population consisted of all women 
who delivered babies in the gynaecological-obstetric service of the CHUD-B. The study included women suffering from hypertension in pregnancy, regardless of the outcome of the pregnancy, also known as hypertensive disorder of pregnancy (HDP) with normalized or non-normalized BP. There are four (04) types of hypertension in pregnancy [12]:

- Pregnancy-induced hypertension: corresponds to the appearance of isolated hypertension, i.e. without proteinuria, after 20 weeks gestation and disappearing within 42 days postpartum.

- Pre-eclampsia: appearance after 20 weeks of gestation of arterial hypertension associated with significant proteinuria ( $\geq 2$ crosses on urine dipstick).

- Chronic hypertension: corresponds to hypertension prior to pregnancy or diagnosed before 20 weeks gestation. Gestational hypertension that persists beyond 6 weeks postpartum is also considered chronic hypertension.

- Superadded pre-eclampsia: the occurrence of significant proteinuria in a chronically hypertensive patient.

Births lost to follow-up and those who did not give informed consent were excluded from the study.

After an exhaustive census of all deliveries fulfilling the above-mentioned inclusion criteria, the sample size consisted of all deliveries with an HDP followed up until the end of the follow-up period.

The dependent variable was represented by the change in HDP after delivery and included the following modalities:

- The change in blood pressure and

- Maternal complications of HDP after delivery.

Table 1 shows the different threshold values for blood pressure control.

For reasons of affordability, self-measurement of blood pressure was preferred to assess the evolution of blood pressure levels in patients with HDP and three evolutionary modalities were selected:

- Normalized BP: if the average blood pressure on self-measurement was less than 135/85 mmHg on two successive visits without taking any antihypertensive medication.

- Controlled hypertension: if the BP has been maintained normal (mean self-measurement blood pressure less than $135 / 85 \mathrm{mmhg}$ ) only with antihypertensive treatment.

- Uncontrolled hypertension: if the BP has remained at or above $140 / 90 \mathrm{mmHg}$ in the office and above $135 / 85 \mathrm{mmHg}$ on self-measurement despite well-conducted antihypertensive treatment.

With regard to maternal complications after childbirth, we have:

- Severe hypertension: defined within 6 weeks of delivery by systolic blood pressure $(\mathrm{SBP}) \geq 160 \mathrm{mmHg}$ and/or diastolic blood pressure $(\mathrm{DBP}) \geq 110$ $\mathrm{mmHg}$ on two occasions 4 hours apart and 06 weeks postpartum by an SBP $\geq 180 \mathrm{mmHg}$ and/or DBP $\geq 110 \mathrm{mmHg}$ [14] [15].

- Eclamptic seizure: tonic-clonic seizures occurring in the setting of pre-eclampsia followed by post-critical coma [16]. 
Table 1. Cut-off values for defining blood pressure profiles of women at inclusion according to measurement methods [13].

\begin{tabular}{|c|c|c|c|c|c|c|}
\hline \multirow{2}{*}{ Blood pressure profile } & \multicolumn{3}{|c|}{$\begin{array}{l}\text { Controlled hypertension } \\
(\mathrm{mmHg})\end{array}$} & \multicolumn{3}{|c|}{$\begin{array}{l}\text { Uncontrolled hypertension } \\
(\mathrm{mmHg})\end{array}$} \\
\hline & SBP & & DBP & SBP & & DBP \\
\hline Office measurement & $<140$ & and & $<90$ & $\geq 140$ & and/or & $\geq 90$ \\
\hline Self-measurement of blood pressure & $<135$ & and & $<85$ & $\geq 135$ & and/or & $\geq 85$ \\
\hline $\mathrm{ABPM}^{*}$ & $<130$ & and & $<80$ & $\geq 130$ & and/or & $\geq 80$ \\
\hline
\end{tabular}

$\mathrm{ABPM}^{*}=$ Ambulatory blood pressure measurement; $\mathrm{SBP}=$ systolic blood pressure $; \mathrm{DBP}=$ diastolic blood pressure.

- Renal failure: oliguria $(<500 \mathrm{ml} / 24 \mathrm{~h})$ with a progressive rise in creatinine levels above $135 \mu \mathrm{mol} / \mathrm{L}[16]$.

- Acute pulmonary oedema (APO) [16].

- HELLP syndrome [16].

- Stroke [16].

- Death [17].

The independent variables were sociodemographic data (age, ethnicity, religion, marital status, education, occupation, residence), antecedents (cardiovascular risk factors, comorbidities), obstetrical data (obstetrical history, type of pregnancy, pregnancy follow-up modalities, outcome of the pregnancy, status of the newborn, occurrence of complications during the pregnancy), the type of HDP (term of discovery of the hypertension, type of hypertension during pregnancy, severity of the hypertension, stability of the hypertension) and the characteristics of the treatment (anti-hypertensive treatment in the post partum period, duration of treatment, compliance with the treatment).

Documentary analysis, individual interview and physical examination were the main techniques used for data collection. All women included had blood pressure, pulse rate, weight and height taken.

The collected data were recorded, processed, and analysed with Epi Data 3.1 and $\mathrm{R}$ studio version 3.6.0 software respectively. A Wald stepwise multiple binary logistic regression was applied. The Hosmer-Lemeshow test was used for the fit of the final model (Table 2). Values of $\mathrm{p}<5 \%$ were considered statistically significant.

\section{Results}

\section{Frequency of HDP in the gynaecological-obstetric service in 2020}

During our study period 298 cases of HDP were admitted to the gynaecological-obstetric service out of a total of 1904 admissions, i.e. a hospital frequency of $15.6 \%$.

\section{Study population and socio-demographic characteristics}

From January to April 2020, 183 cases of HDP were received, of which we enrolled 24 deliveries. From May to July 2020, 115 cases of HDP were received of which we enrolled 84 deliveries. Thus 108 deliveries were included in the study. 
Table 2. Contingency table for the Hosmer-Lemeshow test.

\begin{tabular}{cccccc}
\hline \multirow{2}{*}{ Steps } & \multicolumn{2}{c}{ Persistent BP $=$ No } & \multicolumn{2}{c}{ Persistent BP $=$ Yes } & \multirow{2}{*}{ Total } \\
\cline { 2 - 5 } & Comments & Expected & Comments & Expected & \\
\hline 1 & 18 & 17.9 & 0 & 0,1 & 18 \\
2 & 12 & 12.5 & 1 & 0,5 & 13 \\
3 & 10 & 9.9 & 1 & 1,1 & 11 \\
4 & 6 & 6.2 & 2 & 1,8 & 8 \\
5 & 6 & 5.2 & 2 & 2,8 & 8 \\
6 & 4 & 3.8 & 3 & 3,2 & 7 \\
7 & 2 & 2.8 & 7 & 6,3 & 9 \\
8 & 1 & 0.8 & 6 & 6,2 & 7 \\
\hline
\end{tabular}

Of the 108 deliveries, 26 were excluded for the reasons mentioned above. We therefore have a sample of 82 births (Figure 1).

The average age was $29.3 \pm 6.8$ years with extremes of 16 and 45 years. Female dealers were the most affected in $30.5 \%$ of cases. Women with up to secondary school education represented $47.6 \%$ of the patients. Married women in couples represented $94 \%$ of the study population. Nine out of 10 women lived in urban areas.

\section{In-hospital incidence of HDP types}

The hospital incidence of HDP was $15.6 \%$.

Pre-eclampsia was found in $58.5 \%$ of cases, gestational hypertension in $32.9 \%$, chronic hypertension in $4.9 \%$ and superadded pre-eclampsia in $3.7 \%$ of cases.

Cardiovascular risk factors, co-morbidities and treatment for hypertension

The main cardiovascular risk factors found in the women surveyed were overweight or obesity, a family history of arterial hypertension and a history of arterial hypertension during previous pregnancies as summarised in Table 3. With regard to comorbidities, one of the women was HIV positive1.

In terms of antihypertensive treatment, $49.1 \%$ of the women with HDP had received emergency injectable treatment, followed in all cases by a per os relay. Injectable clonidine and injectable nicardipine were the molecules used in $42.4 \%$ and $10.2 \%$ of cases respectively. Oral alpha methyl dopa was prescribed in all women (100\%) with HDP. Amlodipine was the second antihypertensive drug used in $10.2 \%$ of cases.

With regard to compliance, $45.8 \%$ of the women had good compliance with their antihypertensive medication. $39 \%$ had a minimal compliance problem and $15.2 \%$ had poor compliance.

\section{Evolution of hypertension in the post partum period}

During the follow-up $28 \%$ of the women had presented complications of which $23.2 \%$ were severe hypertension, $3.6 \%$ eclampsia and $1.2 \%$ puerperal psychosis. 


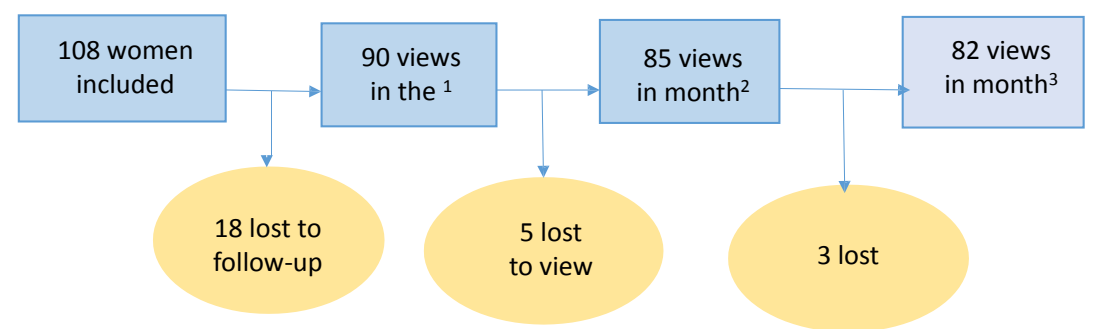

Figure 1. Flowchart of HDP births included in the study and followed for 03 months.

Table 3. Distribution of births surveyed according to cardiovascular risk factors in Parakou in $2020(\mathrm{~N}=82)$.

\begin{tabular}{ccc}
\hline & Numbers $(\mathrm{N}=82)$ & Frequency (\%) \\
\hline Obesity or overweight & 42 & 51.2 \\
Sedentary lifestyle & 45 & 54.9 \\
Family history of hypertension & 26 & 31.7 \\
History of hypertension in previous pregnancies & 19 & 23.2 \\
\hline
\end{tabular}

At the end of the 3-month follow-up, $73.2 \%$ of the women had normalized their blood pressure.

Hypertension persisted in $25.6 \%$ of the women but was controlled with treatment.

Only one woman (1.2\%) had uncontrolled hypertension.

\section{Factors associated with persistent hypertension in the women followed}

In univariate analysis, overweight/obesity, sedentary lifestyle, family history of hypertension and diabetes, history of hypertension in previous pregnancies, maternal complications during pregnancy and poor compliance with medication were significantly associated with persistence of hypertension after HDP in the followed-up women.

Factors associated with persistence of hypertension were overweight or obesity, family history of hypertension, and history of hypertension in previous pregnancies after multivariate analysis (Table 4).

\section{Discussion}

\section{Frequency of HDP in hospitals}

The hospital frequency of HDP found in our study was $15.6 \%$. This frequency is close to the $17.5 \%$ found in Dakar by Tal Dia A. in 2002 [18] and is slightly higher than the $12.6 \%$ reported by Baragou et al. in 2014 in Lomé [19]. This suggests that the prevalence of HDP in sub-Saharan Africa is quite high, ranging from $12 \%$ to $17 \%$. This frequency is however higher than that found by Codjo et al. in 2015 in Parakou (6.2\%) [9]. This can be explained essentially by the diversity of the populations studied. We focused on the women who gave birth at the CHUD-B (monocentric study), whereas Codjo et al. conducted a multicentric study including pregnant women seen in consultation and parturients. 
Table 4. Predictive factors for the persistence of hypertension among women who gave birth to babies with HDP in Parakou in 2020 (multivariate analysis).

\begin{tabular}{cccc}
\hline & $\mathbf{R R}_{\mathbf{a}}$ & IC 95\% RRa & p-value \\
\hline Age (in years) & 1.073 & {$[0.956-1.203]$} & 0.231 \\
Overweight & 8.664 & {$[1.566-47.941]$} & $\mathbf{0 . 0 1 3}$ \\
Family history of hypertension & 6.499 & {$[1.493-28.289]$} & $\mathbf{0 . 0 1 3}$ \\
Notion of hypertension in previous pregnancies & 7.764 & {$[1.561-38.601]$} & $\mathbf{0 . 0 1 2}$ \\
\hline
\end{tabular}

\section{Persistence of hypertension after HDP}

We reported a $26.8 \%$ incidence of persistent hypertension after HDP. This result is similar to that of Kaze et al. in Yaoundé in 2012 who found a prevalence of $27.8 \%$ [20] after using a method similar to ours but taking into account only women who had pre-eclampsia and eclampsia. The frequency found in our work is lower than the $50 \%$ reported by Pechere et al. in Geneva [21]. The latter used ambulatory 24-hour blood pressure measurement (ABPM) for the diagnosis of hypertension 6 to 12 weeks after pre-eclampsia. In doing so they found $17.9 \%$ white coat hypertension and $11.6 \%$ masked hypertension. This highlights the importance of using ambulatory BP measurement techniques for the diagnosis of postpartum hypertension in women with HDP. Hypertension may be misdiagnosed or its prevalence underestimated when measurements are only made in the office. Lower prevalences than ours have been found by Sibai et al. $(14.8 \%)$ in the USA [3] and Festa et al. (10.6\%) in Italy [4]. This difference is explained by the study population and the study period. Our study was carried out on an all-black population which would be more likely to develop hypertension [3]. The Sibai study only included primigravid women with pre-eclampsia or eclampsia who were followed for at least two years. The risk of chronic hypertension after HDP increases as parity increases and even more so in the case of recurrence of pre-eclampsia [6]. This explains the lower rate found by Sibai. Festa et al. who, like us, took into account all types of HDP. However, the patients in this study were followed for a longer period of three years. Studies with longer follow-up show a higher frequency of persistent hypertension [3] [4] [20] [22]. In Yaoundé, Kaze carried out a six-month follow-up which allows us to conclude that the prevalence of hypertension after pre-eclampsia decreases as time goes by ( $42.6 \%$ at six weeks, $27.8 \%$ at 3 months and $14.8 \%$ at 6 months) [20]. According to the literature, gravidic hypertension usually disappears after 6 weeks, whereas hypertension associated with severe pre-eclampsia or eclampsia recedes within 3 to 6 months [23]. However, this decrease in numbers is not reassuring, as even women whose blood pressure normalises in the months following childbirth remain at high cardiovascular risk. Indeed, they are predisposed to develop chronic hypertension, ischaemic heart disease, venous thromboembolism or stroke after a few years [5] [23] [24] [25]. It is therefore essential to follow up all women with HDP and to systematically look for a history of hypertension during pregnancy in all patients seen in cardiology. These women, more than anyone else, must scrupulously respect hygienic and dietary meas- 
ures, particularly a low-salt and low-fat diet, and physical activity in order to actively prevent modifiable cardiovascular risk factors.

\section{Factors associated with persistence}

In our study, obesity or overweight was associated with the persistence of hypertension after delivery in women with HDP. This factor associated with persistence of hypertension was also found by Hwang et al. in South Korea [22], Timpka et al. in the USA [5], Festa et al. in Italy [4], Kaze et al. [20] and Amougou et al. [6] in Cameroon. This similarity is explained by the fact that obesity independently of HDP is a cardiovascular risk factor that potentiates the risk of hypertension. This implies closer monitoring of overweight or obese patients with HDP.

We found that the existence of diabetes or hypertension in the mother or father and siblings of the patient with HDP was associated with the persistence of hypertension after HDP. This result is consistent with that found by Amougou et al. in Cameroon [6]. Genetics is partly responsible for the genesis of chronic and pregnancy-related hypertension. Thus, the presence of a family history of hypertension, especially in first-degree relatives, is recognised as a risk factor for hypertension during pregnancy and primary hypertension.

A history of hypertension in previous pregnancies was associated with the persistence of hypertension in the postpartum period in our study. This is explained by the fact that with each pregnancy women have an increased vascular and metabolic risk and after pregnancy the residual risk is greater in women with pre-eclampsia than in those with a normal pregnancy. With each recurrence of pre-eclampsia, this risk is slightly higher-this is known as "additional memory" of risk [23]. Thus, a woman with her second episode of pre-eclampsia is more likely to develop chronic hypertension than a woman with her first episode. Sibai et al. reached the same conclusion in the USA [3].

\section{Limitations of the Study}

Our study only took into account births hospitalised at the CHUD-B, so the results cannot be extrapolated to the entire population of women who had an HDP.

We also deplore the low participation of the women concerned. Indeed, we had great difficulty in finding patients with HDP who had given birth between January and April 2020. The main reasons for this were unavailable or non-functional telephone numbers, patients travelling or not wishing to take part in the study. Admittedly, the three-month follow-up time was relatively short. We focused much more on the clinical status of the babies. It was not possible to carry out all the paraclinical investigations because they required a financial contribution from the women. This justifies the performance of paraclinical examinations on few participants. All this makes our work a pilot study that should be continued.

Despite these limitations, this study had the merit of addressing the problem of the evolution of HDP after childbirth and allowed us to obtain significant and reliable data that could serve as a basis for more in-depth studies. 


\section{Conclusion}

HDP has a prevalence of $15.6 \%$ among women who delivered at CHUD-B/A in 2020. They are mainly complicated by severe hypertension and eclampsia in the postpartum period. Three months after delivery, $26.8 \%$ of the women followed were still hypertensive and the main factors predicting the persistence of hypertension after an HDP were essentially cardiovascular risk factors, namely: obesity or overweight; family history of hypertension and a history of hypertension during previous pregnancies.

\section{Conflicts of Interest}

The authors declare no conflicts of interest regarding the publication of this paper.

\section{References}

[1] Beaufils, M., Haddad, B. and Bavoux, F. (2006) Hypertension during Pregnancy: Physiopathological Aspects and Long-Term Prognosis. EMC-Obstetrics, 29, 1-13.

[2] Mégevand, N., Berkane, N., Begona Martinez, D. and Pechère-Bertschi, A. (2019) Hypertensive Disorders in Pregnancy. Revue Médicale Suisse, 15, 1603-1606.

[3] Sibai, B.M., El-Nazer, A. and Gonzalez-Ruiz, A. (1986) Severe Preeclampsia-Eclampsia in Young Primigravid Women: Subsequent Pregnancy Outcome and Remote Prognosis. American Journal of Obstetrics \& Gynecology, 155, 1011-1016. https://doi.org/10.5555/uri:pii:0002937886903364

[4] Festa, C., Mattei, L., Bitterman, O., Pintaudi, B., Framarino dei Malatesta, M., Bianchi, P., et al. (2018) Hypertensive Disorders during Pregnancy and 3 Years after Delivery in Women with Gestational Hyperglycemia. Journal of Endocrinological Investigation, 41, 1067-1075. https://doi.org/10.1007/s40618-018-0833-0

[5] Timpka, S., Stuart, J.J., Tanz, L.J., Rimm, E.B., Franks, P.W. and Rich-Edwards, J.W. (2017) Lifestyle in Progression from Hypertensive Disorders of Pregnancy to Chronic Hypertension in Nurses' Health Study II: Observational Cohort Study. BMJ, 358, Article No. j3024. https://doi.org/10.1136/bmj.j3024

[6] Amougou, S.N., Mbita, S.M.M., Danwe, D. and Tebeu, P.-M. (2019) Factor Associated with Progression to Chronic Arterial Hypertension in Women with Preeclampsia in Yaoundé, Cameroon. Pan African Medical Journal, 33, Article No. 200. https://doi.org/10.11604/pamj.2019.33.200.16857

[7] Codjo, H.L., Dohou, S.H.M., Ogboni, H., Amegan, N., Biaou, C.A., Sonou, A., et al. (2020) Frequency of Complications of Arterial Hypertension in Patients Followed in Cardiology in Parakou in 2016. European Scientific Journal, 16, 42-48.

[8] Attolou, V., Takpara, I., Akpovi, J., Avode, G., Martine, N., de Souza, J., et al. (1998) The Different Types of Arterial Hypertension in Beninese Pregnant Women Admitted to the CNHU of Cotonou. Cahiers d'études et de recherches francophones, 8, 347-353.

[9] Codjo, H.L., Hounkponou, F., Djoh, K.I., Dohou, S.H. and Houénassi, D.M. (2016) Prevalence of the Symptomatic Cardiovascular Diseases during the Pregnancy and in Post Partum in Parakou's Hospital Settings in 2015. International Journal of Nano Dimension, 6, 12-15.

[10] Tchaou, B., Salifou, K., Hounkponou, F., Hountovo, S. and Chobli, M. (2012) Man- 
agement of Severe Preeclampsia in the University Hospital of Parakou. The African Journal of Anaesthesiology and Emergency Medicine, 17, 7-10.

[11] Salifou, K., Denakpo, J., Obossou, A., Gassara, I., Sidi, I. and Perrin, R. (2015) Dysfunctions in the Management of Severe Preeclampsia in a Second-Level Referral Hospital (Parakou/Benin). Gynecology Obstetrics, 5, Article No. 324.

https://doi.org/10.4172/2161-0932.1000324

[12] Mounier-Vehier, C. and Delsart, P. (2009) Hypertension in Pregnancy: A Cardiovascular Risk Situation. La Presse Médicale, 38, 600-608.

https://doi.org/10.1016/j.lpm.2008.11.018

[13] Gobin, N., Wuerzner G., Waeber, B. and Burnier, M. (2012) Ambulatory Measurement of Blood Pressure over 24 Hours. Le Forum Médical Suisse, 12, 600-607.

https://doi.org/10.4414/fms.2012.01093

[14] Anne-Laure, M., Mounier-Vehier, C., Amar, J., Boivin, J.M., Denolle, T., Fauvel, J.P., Plu-Bureau, G., et al. (2017) HTA and Pregnancy: Consensus d'Experts de la Société Française d'Hypertension Artérielle (SFHTA).

http://www.sfhta.eu/wp-content/uploads/2017/09/HTA-ET-GROSSESSE_C-Mouni er-Vehier.pdf

[15] Chevallier, A. (2006) Management of Adult Patients with Essential Hypertension. Journal des Maladies Vasculaires, 31, 16-33.

[16] Moujahid, H. (2007) Management of Severe Pre-Eclampsia and Eclampsia in the Surgical Intensive Care Unit. Université Sidi Mohammed Ben Abdellah, Fez.

https://scolarité.fmp-usmba.ac.ma/cdim/mediatheque/thèse/24-07

[17] docThom (2017) Medical Vocabulary. https://www.vocabulaire-medical.fr/encyclopedie/304-mort

[18] Tal Dia, A. (2002) Prognostic Factors of Pregnancy and Childbirth Complications in Adolescent Girls and Their Newborns in Senegal. Santé, 11, 221-228.

[19] Baragou, S., Goeh-Akue, E., Pio, M., Afassinou, Y.M. and Atta, B. (2014) Hypertension and Pregnancy in Lomé (Sub-Saharan Africa): Epidemiological, Diagnostic Aspects and Risk Factors. Annales de Cardiologie et d'Angéiologie, 63, 145-150. https://doi.org/10.1016/j.ancard.2014.05.006

[20] Kaze, F.F., Njukeng, F.A., Kengne, A.-P., Ashuntantang, G., Mbu, R., et al. (2014) Post-Partum Trend in Blood Pressure Levels, Renal Function and Proteinuria in Women with Severe Preeclampsia and Eclampsia in Sub-Saharan Africa: A 6-Months Cohort Study. BMC Pregnancy Childbirth, 14, Article No. 134. https://doi.org/10.1186/1471-2393-14-134

[21] Dayer, M.L., Vocat, A., Ditisheim, A. and Pechere, A. (2013) Renovascular Prognosis of Preeclampsia in Mother and Child. La Revue Médicale Suisse, 9, 1628-1630, 1632.

[22] Hwang, J., Park, S.-J., Oh, S., Chang, S.-A., Lee, S.-C., Park, S.W., et al. (2015) The Risk Factors That Predict Chronic Hypertension after Delivery in Women with a History of Hypertensive Disorders of Pregnancy. Medicine, 94, e1747.

[23] Mounier-Vehier, C. (2016) Hypertensions artérielles de la grossesse: Un nouveau consensus. Bulletin de l Académie Nationale de Médecine, 200, 1453-1463. https://doi.org/10.1016/S0001-4079(19)30616-8

[24] Ray, J.G., Vermeulen, M.J., Schull, M.J. and Redelmeier, D.A. (2005) Santé cardiovasculaire après les syndromes maternels placentaires (CHAMPS): Etude de cohorte rétrospective basée sur la population. The Lancet, 366, 1797-1803.

https://doi.org/10.1016/S0140-6736(05)67726-4 
[25] Bellamy, L., Casas, J.-P., Hingorani, A.D. and Williams, D.J. (2007) Pre-Eclampsia and Risk of Cardiovascular Disease and Cancer in Later Life: Systematic Review and Meta-Analysis. BMJ, 335, Article No. 974.

https://doi.org/10.1136/bmj.39335.385301.BE 